\title{
The Delegate Paradox: Why Polarized Politicians Can Represent Citizens Best
}

\author{
Douglas J. Ahler* David E. Broockman ${ }^{\dagger}$
}

Short title: The Delegate PARAdoX

*Assistant Professor of Political Science, Florida State University, dahlere f su . edu.

${ }^{\dagger}$ Assistant Professor, Stanford Graduate School of Business, dbroockman@ stanford. edu. 


\begin{abstract}
Many advocate for political reforms intended to resolve apparent disjunctures between politicians' ideologically polarized policy positions and citizens' less-polarized policy preferences. We show these apparent disjunctures can arise even when politicians represent their constituencies well, and that resolving them would likely degrade representation. These counterintuitive results arise from a paradox whereby polarized politicians can best represent constituencies comprised of citizens with idiosyncratic preferences. We document this paradox among U.S. House Members, often criticized for excessive polarization. We show that if House Members represented their constituencies' preferences as closely as possible, they would still appear polarized. Moreover, current Members nearly always represent their constituencies better than counterfactual less-polarized Members. A series of experiments confirms that even "moderate" citizens usually prefer ostensibly polarized representatives to many less-polarized alternatives.
\end{abstract}

Keywords: polarization, representation, public opinion, Congress, preference aggregation

We acknowledge the Institute of Governmental Studies at UC Berkeley for support and Nick Carnes for sharing data. We thank Michael Barber, Dave Brady, Devin Caughey, Christian Fong, Josh Kalla, Keith Krehbiel, Gabe Lenz, Neil Malhotra, Nate Persily, Carrie Roush, Rob van Houweling, and seminar participants at Columbia University, MIT, MPSA, the Pew Research Center, and Polmeth for helpful comments. This research was approved by the UC Berkeley Committee for the Protection on Human Subjects. Supplementary materials are available in an appendix in the online edition. Replication data and scripts are available on Dataverse:

http://dx.doi.org/10.7910/DVN/GR7BOP.

Douglas Ahler is an Assistant Professor of Political Science at Florida State University, Tallahassee, FL 32306.

David Broockman is an Assistant Professor of Political Economy at the Stanford Graduate School of Business, Stanford, CA 94305. 
Elite polarization is said to have given rise to a "disconnect" in how politicians represent voters (e.g., Fiorina and Abrams 2009). According to this widespread view, citizens are overwhelmingly ideologically moderate but are represented by ideologically extreme politicians, who are termed "polarized." Not only has understanding the causes of elite polarization become a focus of scholarly inquiry, but major reforms are being carried out in hopes of remedying it. These include changes to parties, campaign finance, elections, and more (e.g., Mann and Ornstein 2013).

In this paper, we show that remedying this apparent ideological "disconnect" between politicians and voters would likely degrade the quality of political representation. Moreover, we show that this apparent "disconnect" would arise even if politicians represented their constituencies' policy preferences as well as possible. These counterintuitive results arise from a novel paradox we identify whereby constituencies comprising citizens with idiosyncratic policy preferences are often best represented by politicians who appear ideologically polarized. We call this the Delegate Paradox, because representatives who represent their constituencies as closely as possible on every issue can appear polarized and out of step ideologically.

To appreciate this Delegate Paradox, consider a single Representative in the U.S. House, Adam Schiff of California's 29th Congressional District. Five actual constituents of this district who responded to the 2009 Cooperative Congressional Election Study are depicted in Table 1. The CCES asked these constituents how they would have voted on five proposals Congress also voted on that year. In terms of the measured left-right ideology calculated from their views on these issues, these five constituents are the median five respondents in that district. ${ }^{1}$ They all answered more questions in a manner indicating a liberal view than a conservative view. As a consequence, all five

${ }^{1}$ As described below, we use a one-dimensional IRT model to estimate constituents' and legislators' ideologies, using the item and discrimination parameters from the Congressional space (Martin, Quinn and Park 2011). The five constituents we show in the table are the median constituents on this measure, when using survey weights. For interpretability, in Table 1 we do not show these scores but instead show the proportion of issues on which each had a liberal view. 
appear just left of center on an ideological continuum calculated from their preferences on these bills. However, like most citizens, these constituents espouse various mixes of liberal and conservative preferences across these bills. In the terminology of much existing literature, supporting a mix of liberal and conservative policies leads these constituents to be measured as "ideologically moderate" and "not polarized." On the other hand, Schiff voted liberally on all five bills; much existing literature would measure this pattern as "ideologically extreme" and "polarized." That legislators like Schiff are measured as more polarized than his median constituent is the state of affairs scholars lament.

Table 1: The Delegate Paradox: An Example of Why "Best Issue Delegates" May Appear Ideologically Extreme

\begin{tabular}{l|ccccc|ccc} 
& \multicolumn{5}{|c|}{ Liberal Survey Response? } & \multicolumn{3}{c}{ Liberal Roll Call Vote? } \\
& Voter 1 & Voter 2 & Voter 3 & Voter 4 & Voter 5 & $\begin{array}{c}\text { Adam Schiff } \\
\text { (D-CA) }\end{array}$ & $\begin{array}{c}\text { Best Issue } \\
\text { Delegate }\end{array}$ & $\begin{array}{c}\text { Hypothetical } \\
\text { Moderate }\end{array}$ \\
\hline Ledbetter Act & 1 & 1 & 0 & 1 & 1 & 1 & 1 & 1 \\
SCHIP & 1 & 1 & 1 & 1 & 0 & 1 & 1 & 1 \\
Stimulus & 1 & 0 & 1 & 0 & 1 & 1 & 1 & 0 \\
$\begin{array}{l}\text { Clean Energy Act } \\
\text { Obamacare }\end{array}$ & 0 & 1 & 1 & 0 & 1 & 1 & 1 & 1 \\
\hline $\begin{array}{l}\text { Measured } \\
\text { Ideology } \\
\begin{array}{l}\text { Measure: Share of } \\
\text { Responses Liberal) }\end{array}\end{array}$ & $\mathbf{0 . 8}$ & $\mathbf{0 . 8}$ & $\mathbf{0 . 8}$ & $\mathbf{0 . 6}$ & $\mathbf{0 . 6}$ & $\mathbf{1}$ & $\mathbf{1}$ & $\mathbf{0 . 8}$ \\
\hline \\
\hline
\end{tabular}

Notes: 0 denotes a conservative survey response or position, and 1 denotes a liberal survey response or position. Data taken from the 2009 CCES. Mean Issue Agreement and Ideological Distance are computed using Equations 1 and 3.

But how would a legislator seeking to be the "Best Issue Delegate" of this simplified 29th District's aggregated preferences vote on each issue? The Delegate Paradox is that such a Best Issue Delegate who votes with the majority of voters' preferences on each issue would also vote in a manner that would make her appear polarized and extreme relative to her constituents. Despite her constituencies' apparent ideological moderation, she would take the liberal position on each of these five bills, as the constituency's median preference on each of these bills is liberal. And indeed, as Table 1 shows, Rep. Schiff voted exactly this way. Yet this consistent pattern of liberal 
votes means that Schiff is measured as ideologically extreme and polarized, like most Members of Congress (MCs) today (e.g., Poole and Rosenthal 1997). ${ }^{2}$

Many scholars and political observers argue that legislators like Schiff should be replaced by legislators whose positions imply a moderate, less polarized ideology, like the Hypothetical Moderate in Table 1. According to the particular concept of quality representation much of the polarization literature uses, Ideological Distance, the Hypothetical Moderate would appear to be a good match for the district's policy preferences. However, she can only achieve this by voting against majority will on at least one issue. It thus seems unlikely that the constituency depicted in Table 1 would prefer this moderate to Schiff-a majority of voters agree with Schiff on more issues.

To generalize from this example and more precisely define our argument, in this paper we show that two ostensibly similar conceptions of how well legislators represent their constituents are theoretically and empirically distinct. The first conception, nearly universal in the polarization literature, is Measured (Unidimensional) Ideological Distance, defined as:

$$
\text { Measured (Unidimensional) Ideological Distance }{ }_{L}=\left|f(L)-\frac{\sum_{c \in C} f(c)}{|C|}\right|,
$$

where $c$ indexes the set of all constituents $C$ in a district; the legislator for that district $L$ and all $c$ have a set of issue positions on yes/no issues $i \in I$; and $f$ is a function that maps their positions on multiple issues to a scalar that corresponds to their measured left-right political ideology. ${ }^{3}$ For ease of exposition, we define $f(c)=\frac{\sum_{i \in I} 1\left(c_{i}=\text { Liberal }\right)}{|I|}$ in our in-text examples, which corresponds to the share of issues on which an actor has a liberal position. ${ }^{4}$

Implementations of $f(c)$ nearly always imply that constituents have moderate ideological pre-

${ }^{2}$ On DW-NOMINATE, Schiff's first dimension score is fairly similar to other Democrats'.

${ }^{3}$ See also Achen's (1978) related discussion of "centrism."

${ }^{4}$ Empirically, this is nearly identical to more sophisticated measures (Fowler and Hall 2012). 
dispositions. When the output of $f$ is centered at 0 , how Polarized legislator $L$ appears,

$$
\text { Measured Polarization }{ }_{L}=|f(L)|
$$

is therefore thought to be a good proxy of how poorly a legislator represents her constituents—even absent of measures of $C$ for those constituents (Fiorina and Abrams 2009). ${ }^{5}$

Much of the literature on polarization interprets high levels of Measured Polarization as indicating that legislators represent their constituents' policy views poorly. In Table SI-1 we give examples of ten publications that argue that legislators who are lower in Measured Polarization are superior to those who are higher in Measured Polarization. Likewise, in Table SI-2, we also give examples of ten respected publications that use Measured Polarization as a measure of how well legislators represent voters.

But there is a second potential way to conceptualize representation, Mean Issue Agreement:

$$
\text { Mean (Observed) Issue Agreement } \text { Ag }_{L}=\frac{\sum_{i \in I} \sum_{c \in C} \mathbf{1}\left(L_{i}=c_{i}\right)}{|I||C|} .
$$

Mean Issue Agreement is the expectation of whether a constituent chosen at random will agree with the legislators' position on an issue chosen at random. Intuitively, higher values of this metric correspond to legislators who vote in a manner more consistent with their constituents' expressed opinions. ${ }^{6}$ A legislator who voted with the median voter in their district on every issue - that con-

${ }^{5}$ This is the conceptualization of polarization the literature on elite polarization nearly uniformly uses (see SI Tables SI-1 and SI-2). There are other conceptualizations and hypothesized consequences of polarization, especially at the mass level. However, this typical conceptualization of elite polarization is the one we critique here.

${ }^{6}$ We set aside for now the question of which issues voters care about most, following the literature we critique. We return to this matter in the discussion. 
stituency's Best Issue Delegate-would have the highest value of Mean Issue Agreement possible for her district.

Influential critiques of how existing politicians represent their constituents and efforts to reform political institutions are premised on noting high levels of Measured Ideological Distance and Measured Polarization. The Delegate Paradox shows that politicians acting like Best Issue Delegates - that is, who maximize Mean Issue Agreement — can also be high on Measured Ideological Distance and Measured Polarization. Moreover, efforts to reduce elite polarization could actually replace existing legislators who represent their constituencies well on issues with alternatives who represent their constituencies worse - that is, reform efforts that successfully reduce Measured Polarization may well reduce Mean Issue Agreement. In this paper, we make two empirical contributions consistent with this possibility.

Our first empirical contribution is to show that the Delegate Paradox operates in the U.S. House of Representatives. Members of Congress (MCs) are often criticized for excessive polarization. Using data from the CCES, at the level of the legislature we show that counterfactual Representatives who represented their constituencies' policy preferences as closely as possible would still appear more ideologically polarized than these constituencies. Moreover, at the level of constituencies, today's MCs nearly always represent their constituencies' issue preferences more closely than counterfactual less-polarized representatives would. Finally, at the level of individual MCs, Members' Ideological Distance from their constituents and their Mean Issue Agreement with their constituents do not consistently correlate; Members who are most out-of-step with their constituents as a result of being polarized, according to existing research, are not consistently less likely to represent their constituents well on issues.

Our second empirical contribution is to show that citizens do not appear to value whether representatives appear closer to them on Measured Ideological Distance. Instead, most reject representatives who appear closer to them on this measure but who are inferior in terms of Issue Agreement. A series of experimental studies shows that citizens reject counterfactual representa- 
tives whose positions imply a similar ideology but do not match their own on individual issues. We also demonstrate externally valid support for this conclusion in the context of the 2016 U.S. presidential election. That voters do not appear to value measured ideological proximity in itself further supports our claim that politicians' apparent ideological distance from constituents is not a sound conceptualization of the representation they provide.

The central implication of our argument is that replacing today's elected officials with alternatives who are measured as more ideologically moderate may worsen representation in voters' eyes. To be clear, we are not arguing that increasing polarization would necessarily improve representation. Rather, the level of elite polarization simply implies very little about how well politicians are representing citizens' views. (In SI-2, we also show that the fact citizens have increased less in measured polarization than have politicians is not sufficient to demonstrate that politicians represent voters more poorly today than they did in the past.) This caveat to conventional wisdom matters because scholars increasingly use polarization (or lack thereof) as a normative standard for assessing the quality of representation that individual legislators — and entire legislatures_-provide citizens. For example, scholarship increasingly assesses the merits of various political reforms on the basis of whether they encourage politicians to take less polarized positions, taking for granted that this would improve representation (see Table SI-2). Our findings cast doubt on that assumption. Before scholars judge whether such institutional changes improve or worsen politicians' representation, we should move beyond merely assessing whether politicians are polarized or not.

\section{The Delegate Paradox in the U.S. House of Representatives}

Conventional wisdom holds that high levels of measured ideological polarization in Congress imply that MCs represent their constituents poorly (e.g., Fiorina and Abrams 2009). We argue this widespread line of reasoning has not sufficiently attended to the distinction between two concepts: similarity in measured ideological dispositions and similarity in views on particular issues. As 
shown in the example in Table 1, Representative Adam Schiff voted with a majority of his constituents on every single issue asked about in the CCES, but he nevertheless appeared much more polarized than his median constituents, as measured on an ideological scale. This is an example of the Delegate Paradox: Schiff appears polarized and ideologically extreme, even though he is voting as a Best Issue Delegate would.

This Delegate Paradox arises because, within a constituency, one ideological side often garners shifting majorities of voters across issues even if few voters consistently favor that side across them all (e.g., Baldassarri and Gelman 2008; Lelkes 2016). Previous work has pointed out this feature of public opinion and speculated about its implications for measuring representation (e.g., Broockman 2016). In this section, we show that the resulting Delegate Paradox indeed operates in the U.S. House. In particular, we demonstrate:

- At the level of a legislature, high measured polarization is not sufficient to establish that issue representation is suboptimal. A U.S. House composed of counterfactual MCs who represented their constituencies' issue preferences as closely as possible would still appear polarized overall and more polarized than citizens.

- At the level of constituencies, issue representation will not necessarily improve if less polarized legislators are elected. Today's MCs usually represent their constituencies' issue preferences better on issues than counterfactual less-polarized MCs would.

- At the level of legislators, the extent to which is a legislator is polarized is typically uninformative about the extent to which she represents her constituents well on issues. The MCs who represent their constituents poorly on individual issues are not consistently the same MCs existing research indicates are polarized relative to their constituents. 


\section{Finding 1: Best Issue Delegates Would Be Polarized}

We first show that even if MCs voted with the majority of their constituency on every individual issue, they would still be measured as polarized overall and significantly more polarized than citizens. This implies that simply finding measured polarization in a legislative body—or even that its members appear more ideologically polarized than citizens-is not sufficient to conclude that legislators represent their constituents poorly. Indeed, they may appear polarized at least in part $a s$ a result of representing their constituents well.

\section{Data and Methods}

Our analysis draws on six years of data from the Cooperative Congressional Election Study, shown in Table $2 .^{7}$ We use the CCES for three reasons. First, each CCES survey asks respondents how they would have voted on individual bills Congress also voted on. We analyze all bills with a roll call vote in the previous House session. The individual bills and the CCES's question wordings are listed in Section SI-4.1. Second, the CCES has a sizable sample in every district. Third, existing literature has used this very same data to argue that MCs represent their constituents poorly because they are more polarized than their districts or constituents. Therefore, our argument holds data sources constant while only varying analytical approaches.

To supplement the statistical power of the CCES, we use multi-level regression with poststratification (MRP) to estimate district opinion on each individual bill. MRP uses demographic profiles of each district from the U.S. Census and data on how respondents of various demographics responded nationally to compute a precise estimate of district support. More details on our MRP procedure are in SI-5.2. There we show that the MRP estimates we use are highly correlated with

\footnotetext{
${ }^{7}$ We do not use the 2006, 2007, and 2014 CCES datasets because there were not enough roll call votes on these surveys that actually came to the floor. Many of the items on these surveys were publicly debated but did not come to a vote in the House, so we do not have MC votes for the bills.
} 
Table 2: CCES Data Used in These Analyses

\begin{tabular}{cccc}
\hline CCES Year & N Respondents & N Issues & Congress \\
\hline 2008 & 32,450 & 9 & 110 th \\
2009 & 13,697 & 5 & 11 th \\
2010 & 55,223 & 9 & 111 th \\
2011 & 20,101 & 5 & 111 th \\
2012 & 54,067 & 5 & 112 th \\
2016 & 64,402 & 7 & 114 th \\
\hline Total & 239,940 Respondent X Years & 40 Issue X Years & - \\
\hline
\end{tabular}

disaggregated estimates one would reach by estimating districts' mean preferences with CCES data alone. Our results are not sensitive to the use of MRP. Note that random measurement error at the individual level would not bias our estimates of these binary district issue medians.

Following existing literature, we use an IRT model to map vectors of roll call votes and issue views to one-dimensional ideological "ideal points" (Martin, Quinn and Park 2011). IRT is similar to factor analysis or DW-NOMINATE. We first determine bills' difficulty and discrimination parameters - the general tendency of MCs to vote conservatively on bill $i$ and the degree to which a vote on bill $i$ predicts MCs' underlying ideology, respectively—using the R package MCMCpack (software for Bayesian inference; Martin, Quinn and Park 2011), using only existing MCs. We then hold fixed these difficulty and discrimination parameters to map citizens and, later, counterfactual representatives into the congressional ideological space using the $\mathrm{R}$ package mirt. ${ }^{8}$ In SI-5.1 we show that our ideology estimates for MCs based on these votes correspond well with

${ }^{8} \mathrm{We}$ fix the item parameters at the elite level in order for our estimates to be most comparable to existing literature, reviewed in Table SI-1. If voters were to be included in item parameter estimation, Jessee (2016) shows that the estimates would be sensitive to the number of respondents in the sample, an undesirable property. Further, as Jessee (2016) shows, citizens appear less ideologically moderate when item parameters are estimated using citizens, so if anything excluding citizens from our estimation makes our analysis more favorable to the literature we critique. mirt maps into a normal distribution. 
DW-NOMINATE scores, both within and across parties.

\section{Results}

To test whether Best Issue Delegates of U.S. House districts would still appear polarized, we first use the MRP estimates to calculate each district's median preference on every issue in every CCES year in every district. We then consider how a hypothetical MC who took exactly those positions would vote and map these Best Issue Delegates into the Congressional space using IRT.

Consistent with the Delegate Paradox, we find that what held for Rep. Schiff's district holds generally: Best Issue Delegates of today's congressional constituencies would be measured as noticeably more ideologically polarized than their districts. Figure 1a plots the density of these hypothetical Best Issue Delegates’ estimated ideology against each constituency's median estimated ideology. Consistent with the polarization literature, district medians cluster near the scale's midpoint, ostensibly indicating that most districts would be best represented by ideological moderates - that is, representatives who are not polarized. However, even the best possible representatives of those districts' aggregated preferences on individual roll-calls appear polarized: their ideal points exhibit the familiar bimodal distribution we observe among today's MCs. ${ }^{9}$ Figure $1 \mathrm{~b}$ generalizes these patterns across years and also depicts actual MCs' estimated ideal points from those years, which also hew to the familiar bimodal distribution. (SI-5.3 shows that Best Issue Delegates would also exhibit strongly one-dimensional votes.) Although actual MCs in the US House are more polarized than Best Issue Delegates would be, especially Republicans, what this analysis establishes is that observing polarization among politicians is not sufficient to establish that they represent voters poorly; Best Issue Delegates would be measured as polarized, too. We next take up the question of whether MCs would necessarily represent voters better if they voted in a way measured as less polarized.

${ }^{9}$ The spikes in the Best Issue Delegate distributions occur because many districts' Best Issue Delegates would have exactly the same pattern of votes on the bills asked about on the CCES. 
Figure 1: Best Issue Delegates Would Be Polarized

(a) Disaggregated by Year of CCES

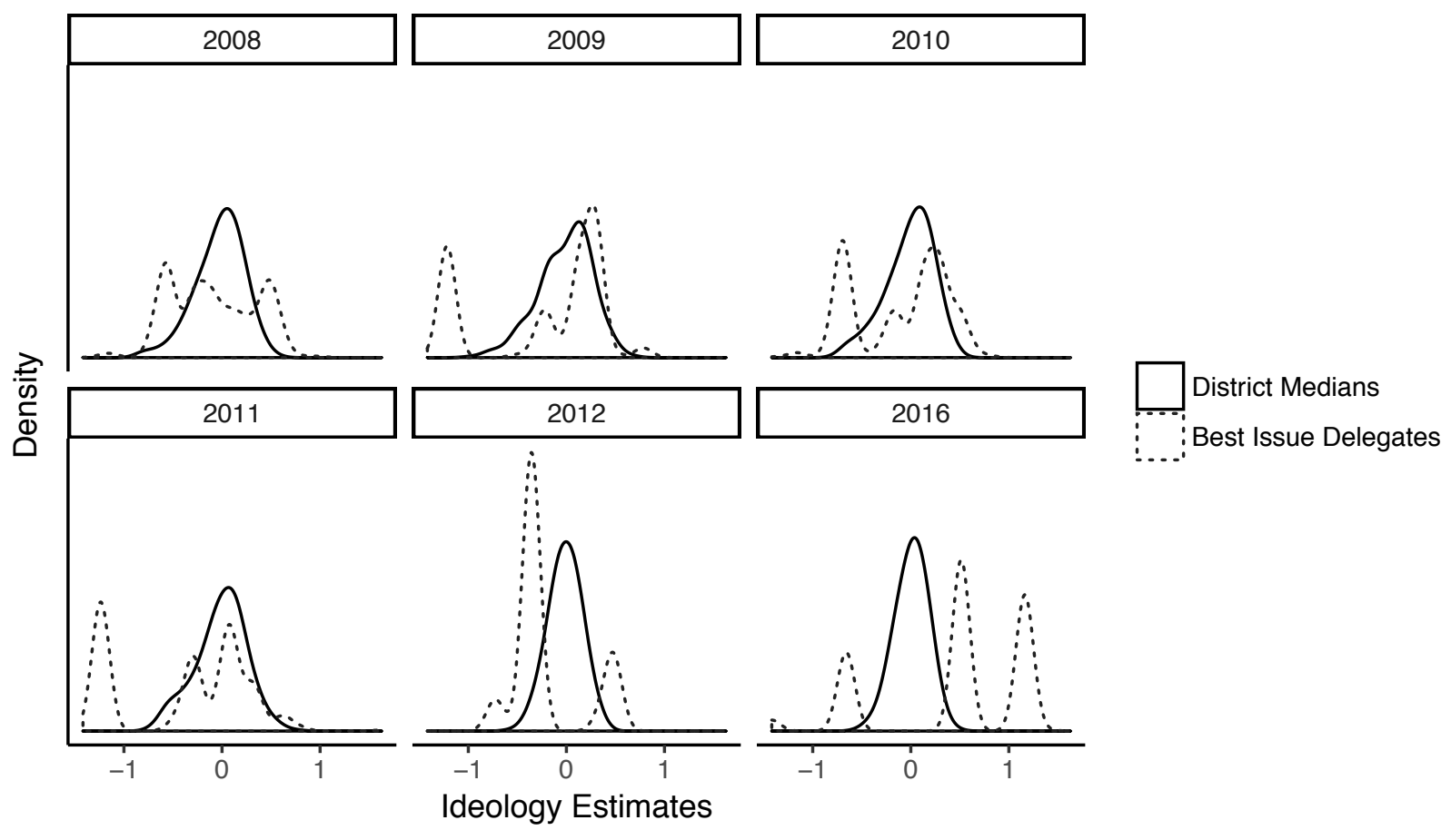

(b) Across Years, with Actual MCs

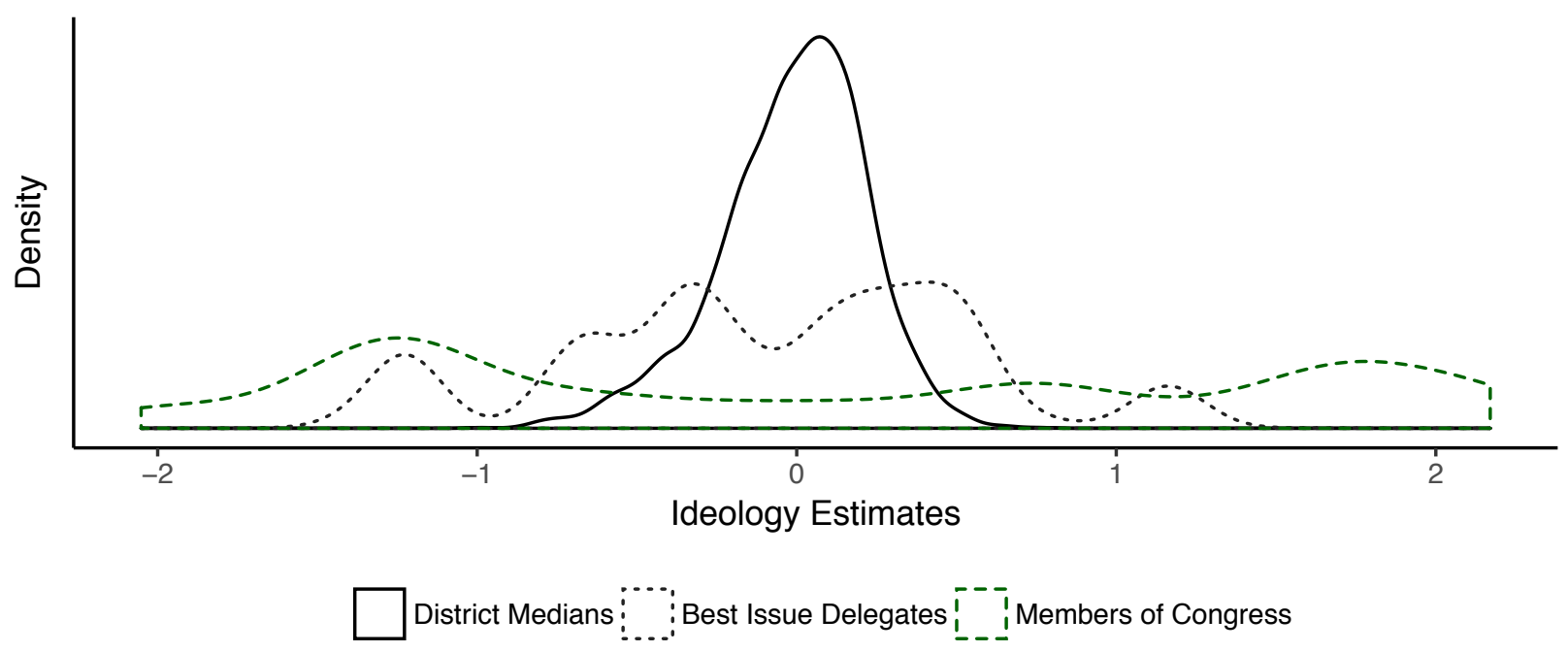




\section{Finding 2: Counterfactual Less-Polarized MCs Are Inferior to Today's MCs}

Conventional wisdom regarding polarization's consequences is that replacing existing MCs with counterfactual MCs who are lower in Measured Polarization would improve representation. We show that most counterfactual MCs who appear less polarized tend to be worse representatives on the issues than existing MCs. Further illustrating the inadequacy of Measured Polarization and Measured Ideological Distance for conceptualizing representation, we also find that counterfactual less-polarized MCs are essentially no better as issue delegates than counterfactual MCs who are even more polarized than existing MCs.

To demonstrate these points, we first consider all possible patterns of votes on the bills under consideration for each district-year (i.e., all combinations of "yay" and "nay" votes on the CCES roll calls). Each of these possible combinations represents a pattern of voting that could be taken by one counterfactual representative. We then estimate the ideological score all possible counterfactual representatives would have received were they in Congress. ${ }^{10}$ We then categorize counterfactual representatives as "ideologically superior" if their measured ideology is more proximate to the district median's measured ideology than the actual MC's, or “ideologically inferior" if their measured ideology is even further from the district median's measured ideology than the current MC's. We also again compute the ideological score for each district-year's Best Issue Delegate.

For clarity, we first present results of this procedure from one district-year-again California's 29th District in 2009, represented by Adam Schiff. Like most citizens, CCES respondents in CA29 (2009) tend to be measured as ideologically moderate. Figure 2a plots the district's estimated mean ideology (in red) against Rep. Schiff's estimated ideal point (in blue), along with the complete distribution of constituents' estimated ideal points. The plot depicts a familiar pattern: the bulk of constituents are concentrated in the ideological center, as is the mean constituent, while Rep. Schiff is quite far to the left. By this ideological metric, Adam Schiff appears to be a poor

\footnotetext{
${ }^{10}$ As previously noted, we hold fixed the item parameters from the Congressional space.
} 
Figure 2: An Example from CA-29 (2009): Polarized MCs Can Best Represent a Constituency

(a)

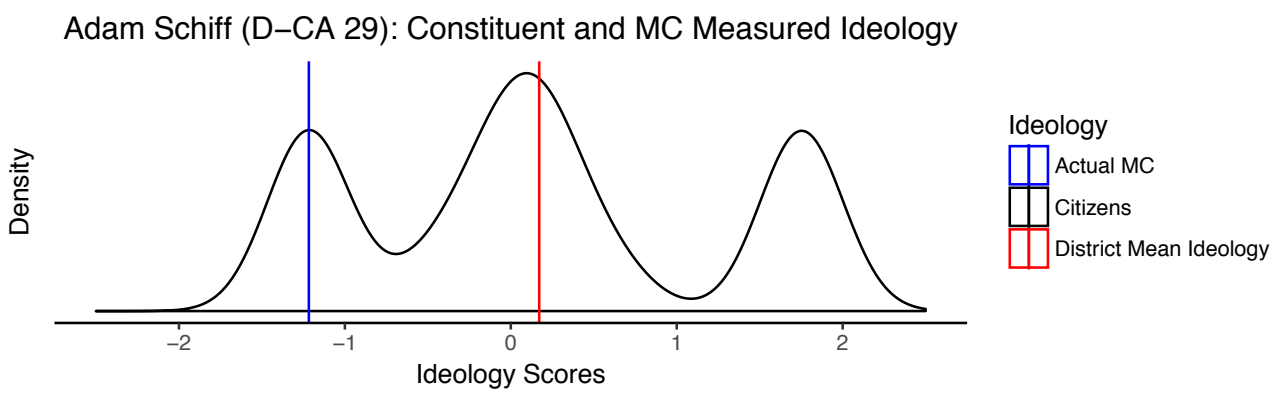

(b)

Adam Schiff (D-CA 29): Issue Representation Provided by Possible Alternative Members of Congress

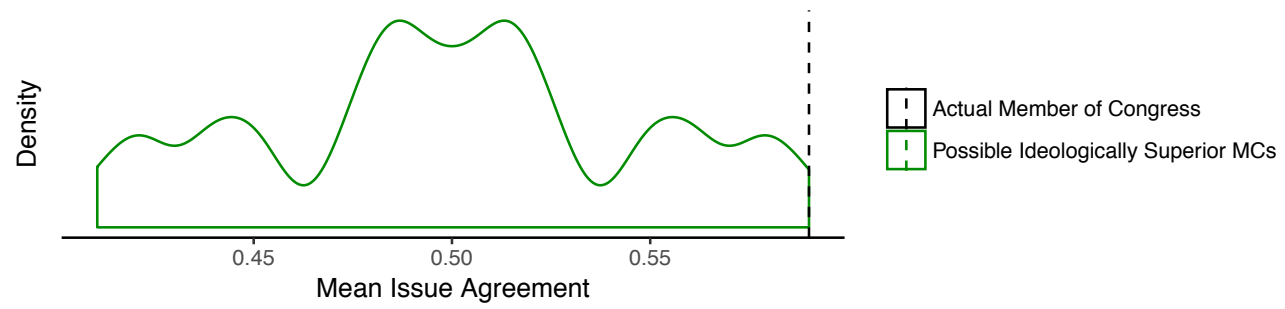

representative of the 29th District; he is too polarized and extreme.

By a different metric, however, Adam Schiff is doing as well as he can to represent his constituency on these roll call votes. Figure $2 \mathrm{~b}$ assesses representation of his constituents' preferences on distinct issues. It plots each possible counterfactual, ideologically-superior representative for the 29th District according to their Mean Issue Agreement. For comparison, it also plots Schiff's score on this metric. Rep. Schiff falls at the rightmost point on the horizontal axis, implying that he represents his constituents better on the issues than all hypothetical, ostensibly ideologically superior representatives.

Figure 3 generalizes these results across MCs and years for which we have data, averaging across districts within years. It shows that contemporary MCs tend to represent their districts quite well on the issues as compared to hypothetical representatives who appear to be better ideological fits. Furthermore, ideologically superior counterfactual representatives tend not to perform any 
Figure 3: Contemporary MCs Better Represent Their Constituencies on the Issues than Nearly All Counterfactual Representatives: Averaging Across Districts Within Years, By Party
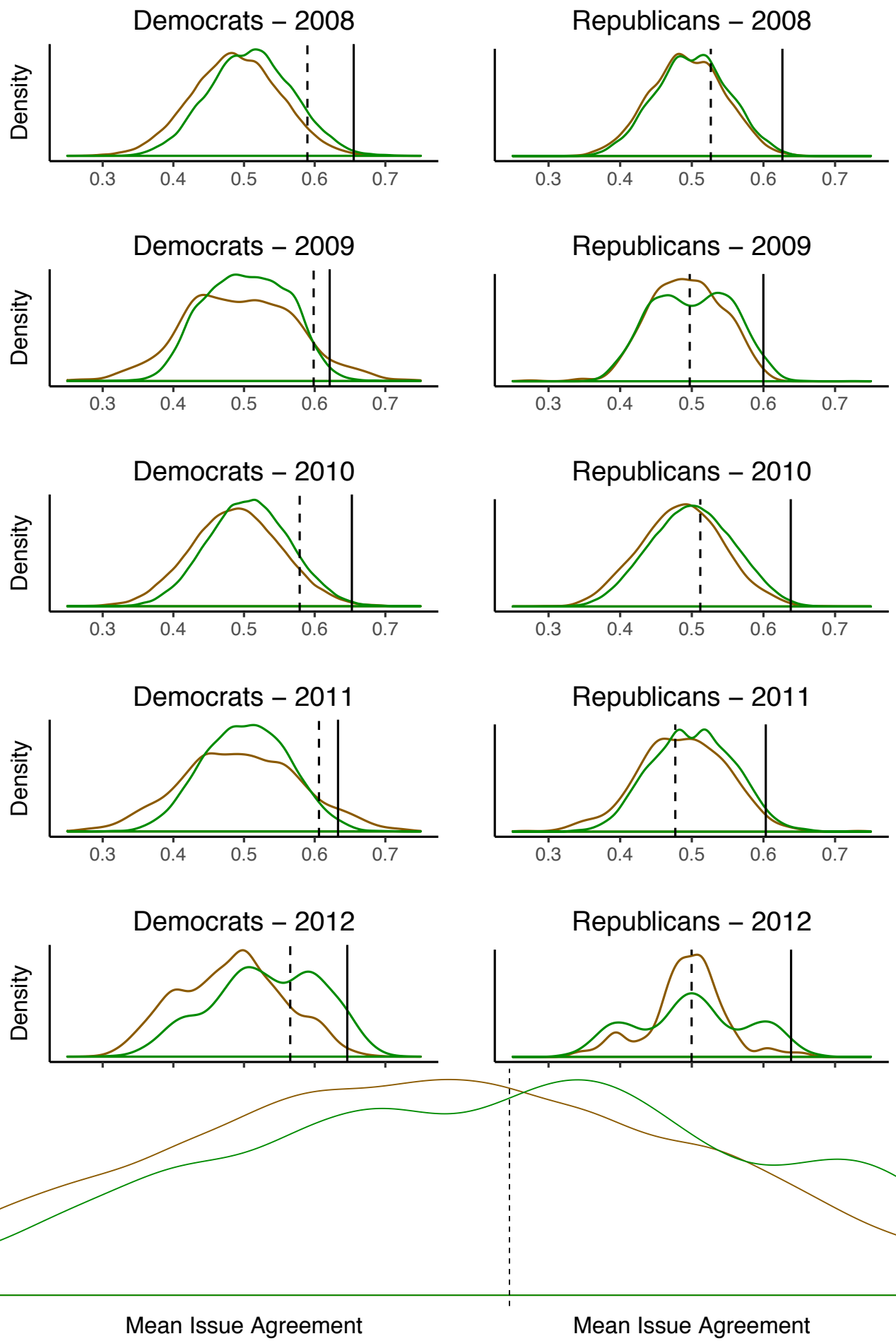

All Counterfactual Representatives $\square$ Possible Ideologically Inferior MCs $\square$ Possible Ideologically Superior MCs

Individual Members of Congress $\quad$ Actual MCs $\mid$ Best Possible Issue Representatives 
better on issue agreement than do ideologically inferior ones.

Part of the reason why counterfactual less-polarized Members of Congress are often inferior to existing Members is that most existing MCs already represent their constituents relatively well on these issues. Although this is certainly not the picture scholars and reformers usually paint, in most years on most issues, we find that legislators vote with the majority of their constituents much more often than not: $69 \%$ of the time for Democrats on average and 52\% of the time for Republicans on average during the years we study. ${ }^{11}$ With this said, some legislators vote with their district medians on issues more often than others. In the next section we ask whether Measured Polarization is able to identify these out-of-step members and find that it is not.

\section{Finding 3: The Quality of Ideological and Issue Representation Members Provide Are Minimally Associated}

We have shown the Delegate Paradox operates at the level of the U.S. House as a whole (Finding 1) and at the level of individual constituencies (Finding 2). We now show that it also operates at the level of individual Members of Congress.

Because constituents' preferences may be summarized within issues or across issues through distinct aggregation processes, Measured Ideological Distance and Mean Issue Agreement could be relatively orthogonal at the Member of Congress level. This would be worrying because a great deal of existing literature uses Measured Polarization and Measured Ideological Distance as measures of how well individual Members represent their constituencies (see Table SI-2).

To compare the existing literature's conceptualization of representation to how well politicians

${ }^{11}$ It may be that a Congressional agenda composed of different bills would yield different conclusions. However, that at least 50\% of CCES respondents say they favor the way Congress decided most bills the CCES has asked about seems inconsistent with the view that Congress has consistently enacted extreme proposals. We discuss this possibility in more detail in SI-3. 
represent their constituents on issues, we compute Mean Ideological Distance and Mean Issue Agreement for every existing Member of Congress in every CCES using Equations 1 and 3. We also compute the Mean Ideological Distance a Best Ideological Delegate would achieve ${ }^{12}$ and the Mean Issue Agreement a Best Issue Delegate would achieve. We then compute the difference between each MC's actual scores on these metrics with the best score they could possibly achieve: Mean Issue Agreement ${ }_{L}-{\text { Mean Issue } \text { Agreement }_{L^{*}} \text { and Mean Ideological Distance }}_{L}-$ Mean Ideological Distance $L_{L^{\prime}}$, where $L$ is the actual legislator, $L^{*}$ is the Best Issue Delegate, and $L^{\prime}$ is the Best Ideological Delegate. We show these two quantities for every MC in every year in Figure 4. Each point represents one MC. Intuitively, these quantities capture how far each MC is from the best possible representation they could provide on each metric.

If the extent to which an MC were polarized or ideologically extreme were a good indication of how well they represented their constituents on issues, we should see strong positive relationships in Figure 4. Instead, these two quantities do not correlate well at the level of individual Members. In some years the sign on the correlation is positive, although the magnitude is rarely strong; in other years, it is negative. There are indeed some MCs who could represent their constituents better on individual issues, but how polarized individual MCs appear does not provide much information about the extent to which this is the case. The Delegate Paradox suggests this is no surprise, as in many districts a legislator can maximize Mean Issue Agreement by taking positions that also increase Ideological Distance. Finding 2 suggests this disjuncture is common, although the severity of it varies by year, potentially as a result of the varying Congressional agenda. ${ }^{13}$

${ }^{12} \mathrm{~A}$ Best Ideological Delegate is defined as the counterfactual legislator of all possible counterfactual legislators with the pattern of votes that minimizes Mean Measured Ideological Distance.

${ }^{13}$ SI-3 shows it is unlikely proposals on the elite agenda are reliably extreme relative to citizens. 
Figure 4: Ideological Representation and Issue Representation Are Minimally Associated

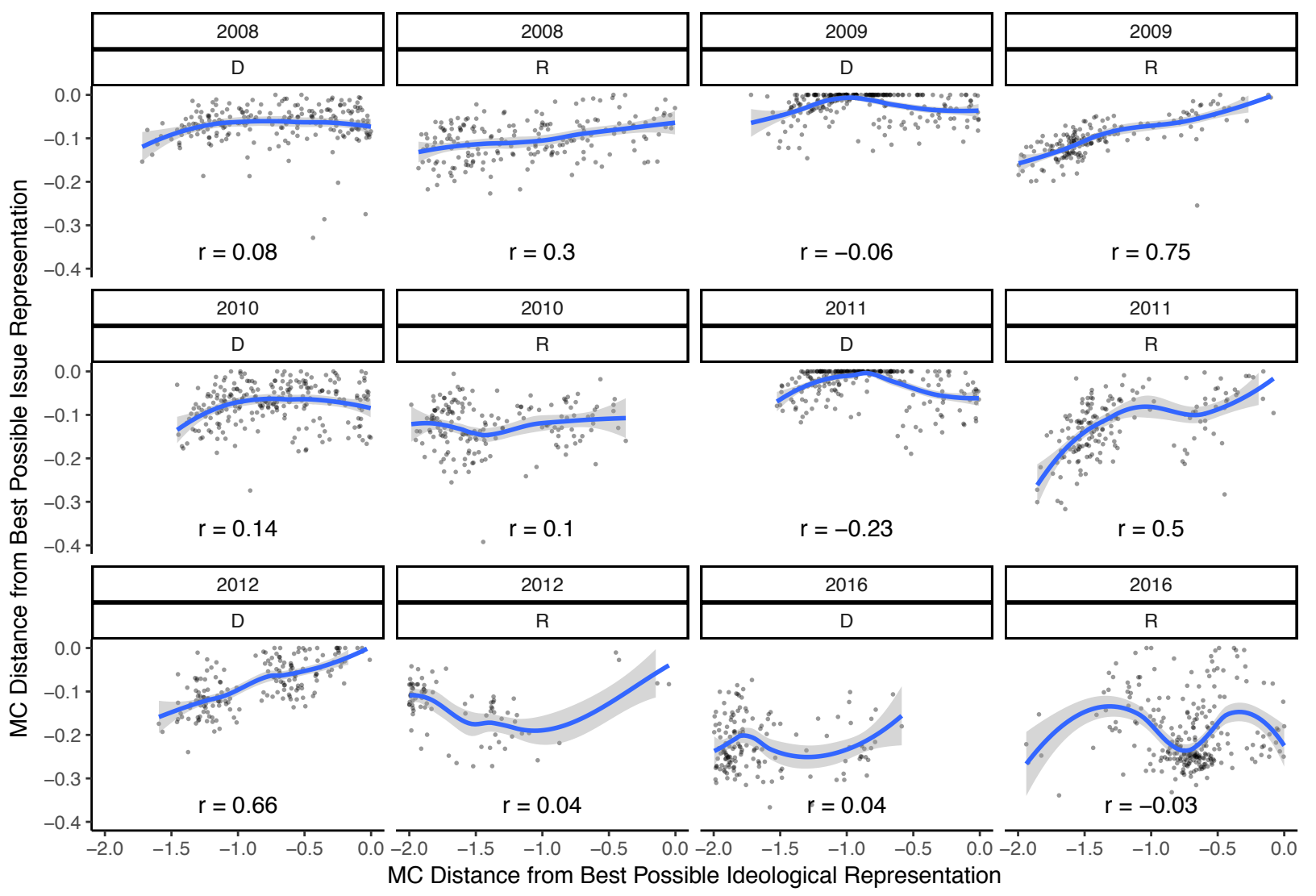

\section{Do Citizens Value Representatives' Ideological Proximity?}

Much of the literature on polarization exclusively uses the yardstick of ideological distance or polarization to gauge the quality of representation politicians provide citizens. However, we showed that how well politicians appear to represent voters ideologically is surprisingly unrelated to how well they represent voters on issues. As a result, elite ideological polarization only implies poor representation if citizens care about seeing their latent ideological preferences represented in Congress or dislike when their MC appears polarized per se. Might citizens do so? Readers already convinced that citizens do not may wish to skip this part of the paper. However, as we have discussed, much of the polarization literature implicitly assumes or explicitly argues exactly this-indeed, despite a tradition of research in political behavior that argues otherwise. Table SI-2 
reviews eleven recent articles in the discipline's top three journals that do so. The literature's analysis generally proceeds as follows: Politicians are polarized because they tend to take positions that are consistently on one side of the ideological spectrum across roll-call votes on different issues. "The average survey respondent appears centrist" because their responses are not so constrained (Ansolabehere and Jones 2010, p. 586). As a consequence, "a majority of the public see themselves as choosing between two parties that are more extreme than they are" (e.g., Fiorina and Abrams 2009), and politicians could “improve the representation of (constituents') views" by “moving to a more moderate position” (e.g., Erikson and Wright 2012).

The assumption that explicitly underpins this line of reasoning is that citizens' views and politicians' positions on individual issues provide windows into an underlying ideology that citizens want their legislators to represent (see Table SI-3 for literature that argues this explicitly). This line of reasoning conceives of answers to policy questions like answers to SAT questions_-primarily revealing a latent unidimensional trait of fundamental importance. This conceptualization allows educational statisticians to describe individuals with one-dimensional summaries-e.g., SAT scores - that "can be compared in a proximate sense" (Bafumi and Herron 2010). The polarization literature has assumed the same about issue questions in political surveys. Two students are said to have nearly identical mathematical ability if they have the same SAT score as computed from their responses to many individual SAT questions. Likewise, two citizens or politicians are said to have nearly identical political views if they have the same ideological ideal point as computed from their responses to many individual issue questions.

The necessary implication of this view is that citizens would welcome the election of politicians with the same calculated ideological ideal point, regardless of whether the views they expressed on the individual issue questions that went into calculating this ideal point were the same. This would render the Delegate Paradox moot, and mean that essentially any counterfactual representatives measured as more ideologically moderate than today's representatives would be superior.

To what extent do citizens evaluate representation of the basis of ideological proximity? Propo- 
nents of the ideological conceptualization of representation point to the fact that citizens are more likely to vote for politicians with similar ideological scores than politicians with dissimilar scores (e.g., Boudreau, Elmendorf and MacKenzie 2015; Jessee 2009). However, this could reflect omitted variable bias instead of genuine ideological voting if citizens have preferences over dimensions that correlate with their measured ideology, such as their issue preferences themselves.

Furthermore, there are reasons to believe that citizens reason about distinct issues on distinct dimensions, rather than according to an underlying liberal-conservative ideology (Broockman 2016; Kinder and Sears 1985). The classic empirical evidence for this view is the low correlations between citizens' views on distinct policies; if an underlying unidimensional ideology really did structure citizens' political judgments, individuals' views on different issues should be more highly correlated than they are (Converse 1964).

However, proponents of the ideological account have noted an alternative explanation for these low correlations: measurement error. This research argues that individuals' responses to issue questions are so rife with measurement error that near-perfect true correlations between their true policy preferences are depressed nearly to zero. As a result, this literature suggests using the scaling techniques described above to estimate citizens' unidimensional ideology — the quantity it argues drives citizens' political choices-from their error-ridden answers to many individual issue questions (e.g., Bafumi and Herron 2010).

Because both sides of this debate have plausible explanations for their own findings and alternative explanations for the other's, we use new methods for assessing how citizens evaluate potential representatives and, ultimately, polarization's consequences for representation.

\section{Data and Methods}

To determine whether citizens want their measured latent ideological preferences represented, we rely on three experiments from a two-wave panel survey conducted in January and March of 2014. We first recruited 1,240 survey respondents from the United States through Survey Sampling In- 
ternational, which recruits samples that compare favorably to Census benchmarks. ${ }^{14}$ In this first survey wave, we asked these respondents 27 binary choice issue questions to which they indicated agreement or disagreement with the statement given (e.g., "Same-sex couples should be allowed to marry"; see SI-4.2.1 for all 27 issue questions). We drew these items from prominent studies that have used them to calculate an ideological scale for the purpose of assessing representation.

We next conducted a follow-up wave in March 2014, to which all Wave 1 respondents were invited and which 513 completed. Wave 2 contained a series of revealed preference experiments, Studies 1-3. In these experiments, we presented citizens with choices between hypothetical potential legislators - constructed from four of the Wave 1 issue questions - and asked them which they preferred. Figure 5 shows an example of this stimulus.

Figure 5: An Example Matchup from Study 1, As Shown to Respondents Imagine choosing between the two candidates for US Congress described below:

\begin{tabular}{|c|c|}
\hline Candidate A & Candidate B \\
\hline $\begin{array}{l}\text { - Support the death penalty in this state. } \\
\text { - Allow illegal immigrants brought to the } \\
\text { US as children to apply for citizenship. } \\
\text { - Legalize the purchase and possession } \\
\text { of small amounts of marijuana. } \\
\text { - Increase taxes for those making over } \\
\$ 250,000 \text { per year. }\end{array}$ & $\begin{array}{l}\text { - Do not allow illegal immigrants brought } \\
\text { to the US as children to apply for } \\
\text { citizenship. } \\
\text { - Do not increase taxes for those making } \\
\text { over } \$ 250,000 \text { per year. } \\
\text { - Prohibit the purchase and possession } \\
\text { of small amounts of marijuana. } \\
\text { - By law, abortion should never be } \\
\text { permitted. }\end{array}$ \\
\hline
\end{tabular}

Please take a few moments to review the candidates' positions and think about the degree to which each candidate reflects your views.

If you had to choose, which candidate would you vote for?

Candidate A

Candidate B

Our analyses examine the relationship between the choices respondents made in Wave 2 and the issue opinions they offered in Wave 1. The gap of two months between the waves was intended

${ }^{14}$ The sample matches the population reasonably well on key demographic variables (see SI5.5). We use survey weights to account for intentional oversampling for another project and to improve the correspondence between the sample and the population on observable covariates. 
to preclude pressure to answer consistently with prior responses.

These experiments provided citizens the option of picking the representatives the polarization literature widely asserts that they would prefer. Since nearly all contemporary Democratic and Republican candidates are polarized, citizens cannot be observed choosing non-polarized politicians in real elections. Thus, their preference for such politicians is typically extrapolated from statistical models with many assumptions. By contrast, we construct hypothetical politicians with the characteristics existing work argues citizens would like-policy positions implying ideological moderation - and observe whether citizens indeed prefer them.

These revealed preference experiments were not focused on explaining electoral choice or in simulating an election. Rather, they allowed us to infer how citizens evaluate representation. As Tausanovitch and Warshaw (2013) note, for ideological ideal points to be valid descriptions of citizens" preferences, it "must be true that [citizens] would choose" a "policy bundle" at their ideal point "over any other one in a pairwise comparison." Would they?

\section{Study 1: Two Politicians With Four Random Issue Positions}

In Study 1, we gave citizens a choice between two politicians with randomly varied issue positions (and, as a consequence, randomly varied implied ideological dispositions). For each of the two politicians shown to each respondent, we first picked four issues at random from the 27 from the Wave 1 survey and then assigned the politicians to either the liberal or conservative position on each issue (independently and with equal probability). We used this setup to examine whether citizens have a preference for representatives who are measured to be more ideologically similar. Some respondents saw politicians whose issue positions did not match their own previously stated positions, yet who did map to a similar ideological ideal point using the polarization literature's methods. The question is whether respondents would tend to prefer such politicians.

We calculated the independent and dependent variables as follows. Respondents' own issue 
and ideological preferences were measured on the basis of their Wave 1 responses. ${ }^{15}$ Politician $B$ 's issue agreement advantage is a simple fraction-the proportion of positions for which the respondent's Wave 1 responses agreed with Politician B's positions minus that same proportion for Politician A. ${ }^{16}$ Politician B's ideological proximity advantage is the probability that Politician B's ideal point $\left(\psi_{B}\right)$ is ideologically closer than Politician A's $\left(\psi_{A}\right)$ to respondent $i$ 's ideal point $\left(\theta_{i}\right){ }^{17}$ The dependent variable is the politician the respondent chose $(A=0, B=1)$.

The two conceptualizations of representation we study provide two ways to map a pattern of legislator positions and citizen survey responses to a scalar measuring similarity between the legislator and the citizen, and we examine which scalar better explains citizens' observed choices. At first glance, ideological similarity seems to affect citizens' choices. Figure 6a demonstrates a significant bivariate association between citizens' ideological proximity to Politician B and a preference for Politician B. However, as we noted, an alternative is also possible: when evaluating politicians on the basis of issues, citizens may sometimes make ideologically proximate choices, even if they care little about ideology in and of itself. Study 1 provides evidence for precisely this. Figure $6 \mathrm{~b}$ plots the same relationship as Figure $6 \mathrm{a}$, but at distinct levels of issue agreement advantage for Politician B (from +2 to -2 ; match-ups further to the right mean Politician B's positions match the respondents' more often than do Politician A's). To the extent citizens care about ideological fit in and of itself, each panel of Figure $6 \mathrm{~b}$ should show the same upward sloping pattern we

${ }^{15}$ We use MCMCpack to generate 10,000 draws from a posterior distribution of each respondent's estimated ideal point.

${ }^{16}$ More precisely, citizen $i$ 's agreement score with Politician A is Agreement $_{i A}=\frac{\Sigma_{j=1}^{j=n}\left(j_{i}=j_{A}\right)}{n}$, with $j$ indexing the randomly chosen issues and $n$ referring to the set of those issues for which the respondent expressed a Wave 1 opinion ( $n=4$ for all respondents). Our main measure of issue congruence in this test is Politician B's issue agreement advantage, Agreement ${ }_{i B}-$ Agreement $_{i A}$.

${ }^{17}$ This is calculated as $\operatorname{Pr}($ Politician B is more proximate $)=\frac{\sum_{d=1}^{10,000}\left|\theta_{i d}-\psi_{B d}\right|<\left|\theta_{i d}-\psi_{A d}\right|}{10,000}$, where $d$ indexes draws from the posterior distributions. 
Figure 6: Ideological Proximity Does Not Predict Respondent Choice Conditional On Issue Agreement

(a) Unconditional Relationship Between Ideological Proximity and Voter Choice

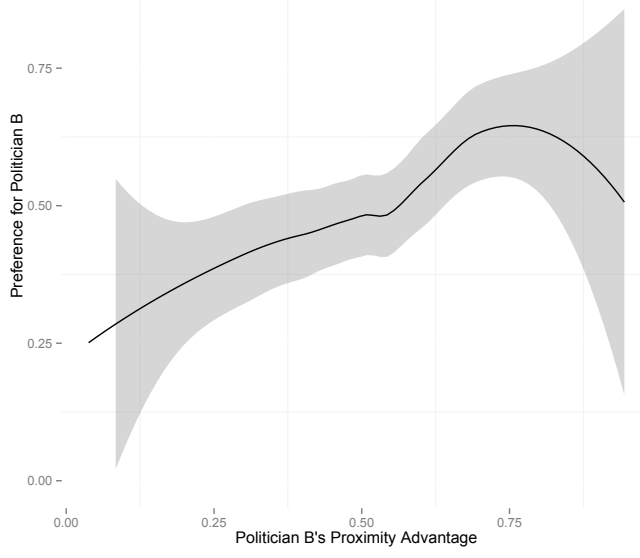

(b) Relationship Between Ideological Proximity and Respondent Choice, Conditional On Issue Agreement
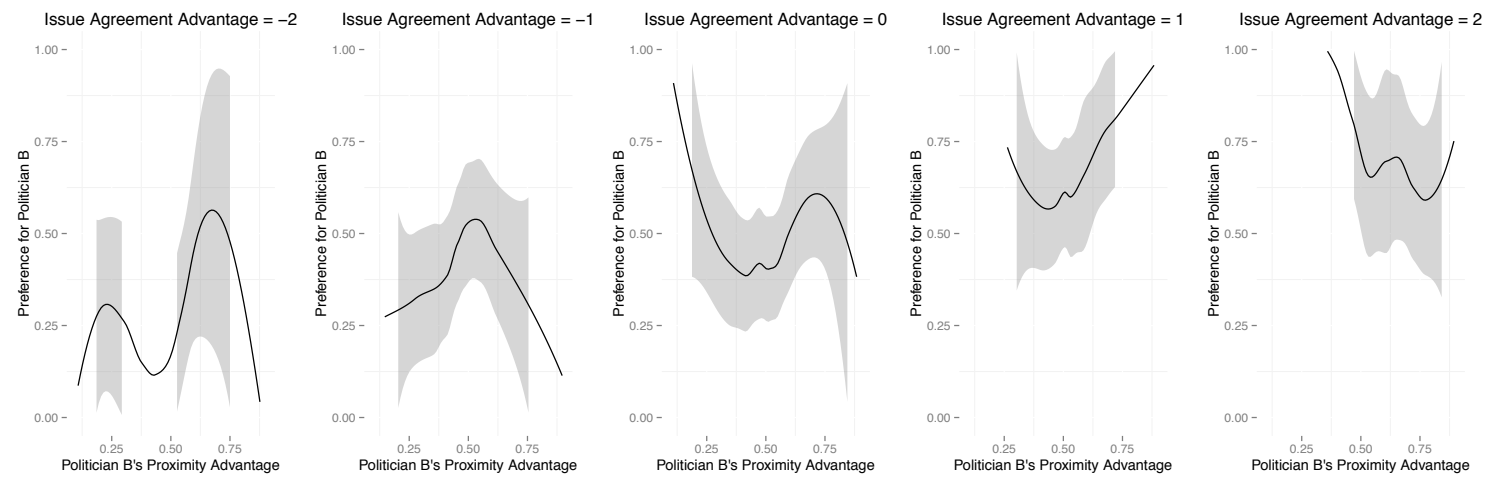

Note: Each graph shows the relationship between the probability that a respondent selected Politician B and Politician B's ideological proximity advantage. Each panel of Figure $6 \mathrm{~b}$ plots this relationship at a different level of issue agreement advantage for Politician B, from lowest levels of agreement advantage with the respondent (on the left) to highest issue agreement advantage (on the right).

observe in Figure 6a, with ideological proximity predicting choice conditional on issue agreement. Instead, we observe a pattern more consistent with citizens only evaluating politicians on the basis of individual issues. Respondents in the subplots to the left saw matchups in which Politician A was a superior match than Politician B on issues and tended to select Politician A; respondents in the subplots to the right saw matchups where Politician B was a superior match on issues and tended 
to select Politician B. Within these subplots that condition on issue agreement, we fail to find any systematic influence of Politician B's ideological advantage on respondents' choices. Table SI5 summarizes this with OLS: controlling for issue agreement, the apparent effect of ideological proximity plummets to near zero, while issue agreement strongly predicts citizens' preferences. In other words, when agreement on issues is no longer perfectly correlated with unidimensional ideological agreement — and not omitted from analysis-evidence that citizens prefer politicians who have similar measured unidimensional ideological dispositions evaporates.

\section{Study 2: Two Politicians with Tailored Issue and Ideological Positions}

Study 1 suggested that citizens' apparent preference for "ideologically proximate" politicians might simply reflect their tendency to agree with such politicians on more individual issues. In Study 2, we more directly pitted the null hypothesis that citizens prefer politicians with similar measured ideological dispositions against the alternative that citizens prioritize issue agreement. In particular, after they completed Study $1,{ }^{18}$ we gave respondents a choice between: 1) an "ideologically correct" politician whose calculated ideological disposition was similar to respondents' own yet entirely disagreed with their Wave 1 issue responses and 2) an "ideologically incorrect" politician who took four positions the respondent reported in Wave 1 but had a dissimilar implied ideological ideal point.

Table 3 shows a simplified example of how such a match-up is possible. The hypothetical respondent gave a liberal response to the first four issue questions in a survey and a conservative response to the second four. The first politician has a conservative view on all four issues shown, making her an extreme conservative and the "ideologically incorrect" choice for the moderate voter. However, this politician's positions on these issues also agree with the respondent's previous stances on all four. On the other hand, the second politician is "ideologically correct" for

\footnotetext{
${ }^{18}$ See Figure SI-9 for a visual depiction of respondents' flow through the studies.
} 
Table 3: Example Matchup From Study 2 (If Wave 1 Had 8 Items)

\begin{tabular}{c|c|cc} 
Issue & $\begin{array}{c}\text { Voter Survey } \\
\text { Response } \\
\text { in Wave 1 }\end{array}$ & $\begin{array}{c}\text { "Ideologically Incorrect" } \\
\text { Politician Position } \\
\text { in Wave 2 }\end{array}$ & $\begin{array}{c}\text { "Ideologically Correct" } \\
\text { Politician Position } \\
\text { in Wave 2 }\end{array}$ \\
\hline 1 & 0 & 0 & - \\
2 & 0 & 0 & - \\
3 & 0 & 0 & 1 \\
4 & 0 & 0 & 1 \\
5 & 1 & - & 0 \\
6 & 1 & - & 0 \\
7 & 1 & - & - \\
8 & 1 & - & -
\end{tabular}

the respondent given their prior responses—-both are perfect ideological moderates—but her positions are at odds with the respondent's previously stated views on each issue. ${ }^{19}$ This respondent thus faces exactly the choice we believe polarization theories must reckon with: does it necessarily improve representation when politicians who are measured as polarized but agree with their constituencies on many issues are replaced by politicians that are measured as less polarized but might disagree on particular issues more often?

We constructed such tailored match-ups for each respondent as follows, using the same techniques and making the same assumptions as existing literature. To construct the "ideologically correct" politicians, we considered every possible hypothetical politician who took positions on four of the 27 issues, all of which disagreed with a particular respondent's previously reported positions. We then selected from these the politician who was closest to the respondent on latent ideology as indicated by IRT. ${ }^{20}$ To select the "ideologically incorrect" politician, we then exam-

${ }^{19}$ In this simplified example we assume all items have equal difficulty and discrimination parameters. For the experiments, we map individual item responses to a single dimension using IRT and do not make this assumption, scaling small groups of possible candidates with all respondents.

${ }^{20} \mathrm{We}$ minimized the mean squared distance between the respondent and politician across the draws from the posterior. 
ined the universe of all possible politicians with four positions the same as the respondents' but the most likely to be inferior from an ideological perspective to the "ideologically correct" politician already selected. ${ }^{21}$ SI-4.4 describes this process in greater detail and Figure SI-10 shows this process graphically. As in Study 1, we asked citizens to choose between these two politicians. ${ }^{22}$

\section{Results}

A minority of respondents opted for the politician who was measured to be more ideologically proximate to them. A majority of respondents instead preferred a polarized politician who agreed with their previously stated issue positions. $66.9 \%$ of the 132 respondents in Study 2 selected the “ideologically incorrect" politician, while just 33.1\% selected the "ideologically correct" politician (95\% CI: $[20.1 \%, 46.2 \%])$. One reason these results are surprising is that citizens who lean right or lean left should have usually inferred that the "ideologically correct" choice shared their party and their views on other issues. Yet, only a third select this politician.

\section{Study 3: Robustness to Priming and Providing Ideology}

A potential alternative explanation for these results is that respondents would have preferred an ideologically similar politician but failed to identify "what goes with what" ideologically (e.g.,

${ }^{21}$ We classified our procedure as successful if $\operatorname{Pr}$ ( "Ideologically correct" politician is ideologically superior $) \geq 0.75$. This resulted in $8 \%$ of respondents' non-participation in Studies $2-3$ because their views were already so ideologically consistent it was impossible to compute a politician who shared a similar measured ideology but had diverging issue views. Both we and the literature we critique believe these citizens are already well-represented by politicians measured as polarized and do not have diverging predictions about their behavior.

${ }^{22}$ We randomly assigned whether "ideologically correct" and "ideologically incorrect" politicians occupied the positions of "Politician A" or "Politician B." 
Converse 1964), and therefore failed to identify ideologically proximate politicians. SI-5.6 shows that respondents were able to estimate the politicians' ideologies much better than chance in Study 2. However, we also assess this possibility with a series of ideological treatments randomly assigned prior to choosing between the two politicians.

Our first two treatments were relatively indirect. In the first, 122 respondents were asked whether Politician A would agree or disagree with 5 other issue statements, meant to lead respondents to think about how issues fit together. In the second, 123 respondents were asked to place both politicians on a standard 7-point ideological scale, thus priming ideological thinking.

Our final and most direct treatment also showed 127 respondents a visual representation of the ideal point estimates for the two politicians. We told them, "Based on these positions, scholars believe these two politicians are at about the positions shown on a liberal-conservative spectrum." This treatment should leave no doubt as to the ideological aspect of the choice respondents faced. Indeed, many studies capture citizens' views by asking them to place themselves and politicians on scales just like this (see Table SI-3). Likewise, thinking that voters would view such visuals as informative, researchers famously sent such a depiction of judicial candidates' ideologies to tens of thousands of Montana voters ahead of a judicial election (Willis 2014). Thus, many scholars appear to believe that citizens seek out candidates with similar measured ideologies with this sort of visual aid available.

As Figure 8 shows, none of these interventions led citizens to prefer the more ideologically proximate candidate. Pooling across conditions, just $31.1 \%$ of respondents selected said candidate (95\% CI: $[24.9,37.2]){ }^{23}$ This is difficult to reconcile with the view that citizens roundly reject politicians who measure as ideologically extreme and would prefer politicians who do not.

\footnotetext{
${ }^{23}$ Respondents with higher values of $\operatorname{Pr}$ ("Ideologically correct" politician is ideologically superior were no more likely to select the ideologically correct politician; see SI-5.7.
} 
Figure 7: Example of "Ideology Shown" Condition

Based on these positions, scholars believe these two candidates are at about the positions shown below on a liberal-conservative spectrum:

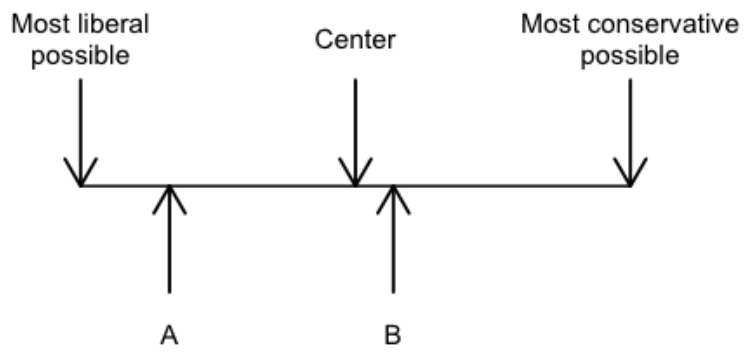

In this example, politician B is the respondent's "ideologically correct" politician who nevertheless disagrees with the respondent on all four issues, while politician A is the respondent's "ideologically incorrect" politician who agrees with the respondent on all four issues.

Figure 8: Priming or Providing Ideology Fails to Increase Demand for Ideological Representation

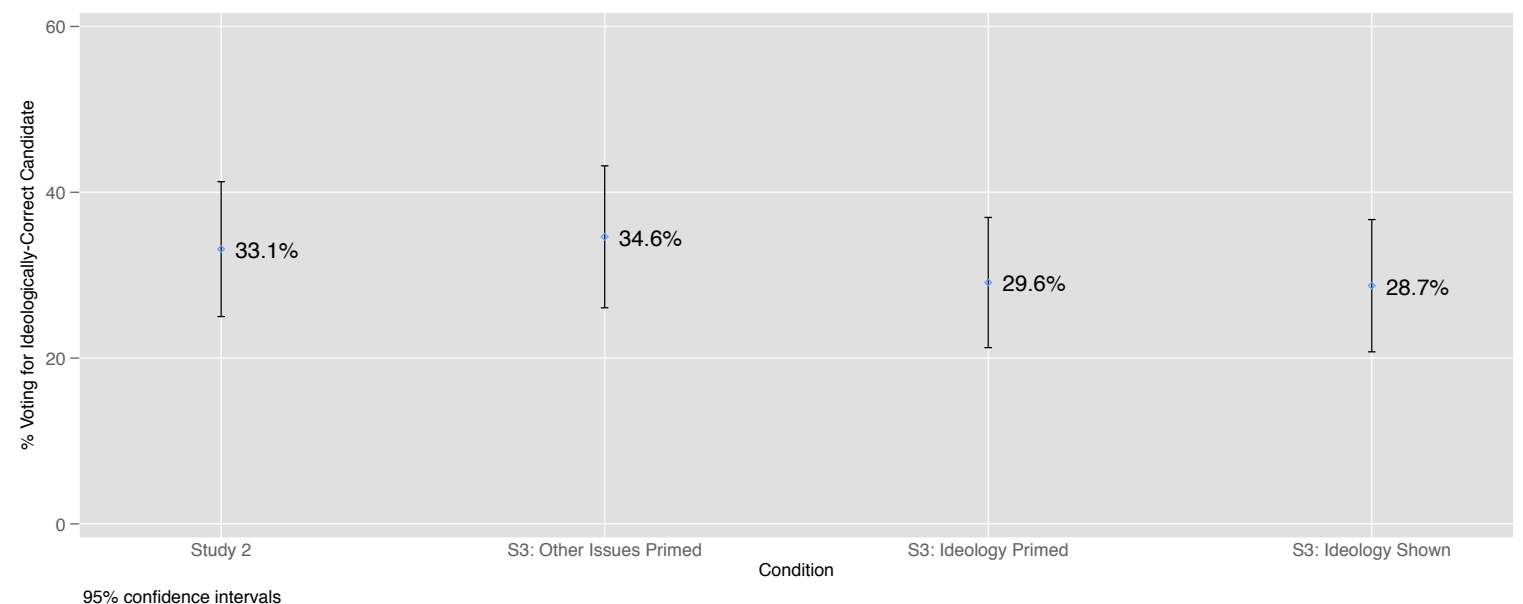

\section{Discussion of Studies 1-3: Apparent Ideological Preferences Are an Artifact of Issue Preferences}

Citizens tend to express a mix of liberal and conservative views across issues, and score low on measured ideological polarization. The polarization literature often argues that citizens would be more satisfied with representatives with similarly mixed positions. However, when we presented citizens politicians who met this criteria, they did not appear to gravitate to them; they tend to 
prefer politicians who match their issue views, regardless of the ideology those positions imply.

These experiments expose the behavioral underpinnings of the Delegate Paradox. The polarization literature asks, "Why do representatives stray so far from their constituencies' moderate median measured ideology?" The previous sections demonstrate that they may do so strategicallycounterintuitively, to maximize representation of their constituency's aggregated preferences on distinct issues. But for this to be true, their constituents would have to evaluate policy representation according to their distinct preferences on distinct issues, rather than on a latent ideological dimension. We find this to be the case. This is consistent with our argument that politicians who appear "polarized" may be maximizing what is most meaningful to citizens.

\section{Study 4: An Application To Donald Trump's Presidential Candidacy}

Hypotheticals inevitably raise questions about external validity. Could a real politician with a mix of positions on the left and right win support from citizens who do not share that politician's views but who also are measured as moderate? This is what the polarization literature necessarily predicts. Donald Trump's presidential candidacy provided unexpected real-world leverage over this question. Despite many extreme positions on individual issues, Trump himself measured as more ideologically moderate than other 2016 Republican Presidential candidates: Trump regularly spurned party orthodoxy. Using similar methods as those used to scale respondents and politicians in Studies 1-3 (Bonica 2014), CrowdPAC thus rated Trump as far more moderate and less polarized than the other Republican presidential candidates on its ideological scale. ${ }^{24}$

Despite being measured as an ideological moderate, we did not expect that citizens who also have a mix of liberal and conservative positions would widely prefer Trump for this reason. Rather, we expected people who share Trump's particular set of liberal and conservative positions to be his

\footnotetext{
${ }^{24} \mathrm{As}$ of December 2015, at https://www.crowdpac.com/elections/ 2016-presidential-election.
} 
strongest supporters. To test this hypothesis, we surveyed 933 Americans through SSI in October 2015. As in Experiments 1-3, we computed a measure of respondents' latent ideology based on their responses to a battery of issue questions. (We folded these ideal point estimates to create a measure of ideological moderation.) We also asked additional questions about two policies where Trump's positions have departed notably from party orthodoxy: to a third of the sample, immigration (an issue on which Trump's position was clearly very conservative) and, to the whole sample, taxes (where Trump's position was ambiguous but his rhetoric was to the left of the GOP). ${ }^{25}$

These data suggest that Trump's issue stances and not his ostensibly moderate unidimensional ideology won him support during the primaries. Table 4 reports a regression in which we use respondents' calculated ideological moderation, conservatism on immigration, and conservatism on taxes to predict their probability of supporting Trump, as measured by a binary vote choice indicator. The first column indicates that ideological moderation positively predicts support for Trump within both parties. Despite this, moderate views on individual issues do not correlate with Trump support. Rather, conservatism on immigration strongly predicts Trump support, as does liberalism on taxes. In addition, when we include all these predictors in one regression, the predictive power of respondents' unidimensional ideology disappears, just as it did in Study $1 .^{26}$

The point we hope to make with this result is how scholars may be led astray if they focus on maximizing the measured ideological moderation of elected officials. It would be facetious to anoint Trump as representing the vast majority of Americans very closely because his ideologically mixed pattern of views leads him to be measured as ideologically moderate. But, as a corollary, scholars should not assume that the public would broadly welcome the election of other politicians measured as ideologically moderate either. Politicians measured as moderate can have wildly

${ }^{25}$ A 7-point scale measured positions on taxes. An index of ten binary items measured positions on immigration. See SI-4.6.

${ }^{26}$ With this said, it remains possible that Trump support could be better conceptualized in terms of multidimensional ideology or non-policy concerns. 
Table 4: Extreme Issue Positions, not Ideological Dispositions, Predict Trump Support

\begin{tabular}{|c|c|c|c|c|}
\hline & \multicolumn{4}{|c|}{ DV: Support for Donald Trump (Binary) } \\
\hline & (1) & (2) & (3) & (4) \\
\hline \multirow{4}{*}{$\begin{array}{l}\text { Measured ideological } \\
\text { moderation } \\
\text { Conservatism on immigration }\end{array}$} & $0.05^{* *}$ & & & 0.06 \\
\hline & $(0.02)$ & & & $(0.05)$ \\
\hline & & $0.29 * * *$ & & $0.29 * * *$ \\
\hline & & $(0.08)$ & & $(0.08)$ \\
\hline \multirow{2}{*}{ Conservatism on taxes } & & & -0.02 & $-0.18 * *$ \\
\hline & & & $(0.04)$ & $(0.08)$ \\
\hline \multirow[t]{2}{*}{ Republican } & $0.17 * * *$ & $0.16 * *$ & 0.16 & $0.21 * * *$ \\
\hline & $(0.04)$ & $(0.07)$ & $(0.04)$ & $(0.07)$ \\
\hline \multirow[t]{2}{*}{ Democrat } & $-0.20 * * *$ & $-0.20 * * *$ & $-0.21 * * *$ & $-0.20 * * *$ \\
\hline & $(0.03)$ & $(0.06)$ & $(0.03)$ & $(0.06)$ \\
\hline \multirow[t]{2}{*}{ Constant } & 0.12 & 0.17 & 0.16 & 0.07 \\
\hline & $(0.07)$ & $(0.07)$ & $(0.04)$ & $(0.15)$ \\
\hline Observations & 933 & 317 & 933 & 317 \\
\hline$R^{2}$ & 0.16 & 0.22 & 0.16 & 0.24 \\
\hline
\end{tabular}

differing political views on different issues which may or may not reflect what citizens measured as moderate prefer.

\section{Discussion}

Conventional wisdom holds that high levels of measured elite polarization indicate that politicians poorly represent citizens' policy views. Politicians vote in ideological lockstep across issues, which is said to leave the bulk of citizens-who tend to report mixes of liberal and conservative views_facing a "dearth of representation" (e.g., Bafumi and Herron 2010, p. 519). Reformers have seized upon this wisdom to make changes to American political institutions intended to encourage the election of politicians measured as ideologically moderate. ${ }^{27}$

${ }^{27}$ These reforms are often significant and costly. For example, reformers have enacted changes to primary election rules in several states under the assumption that these changes can reduce 
We have shown that the election of politicians measured as moderate would likely make representation of Americans' issue views worse. Furthermore, Congress would still appear polarized and ideologically extreme relative to citizens even if it were composed of the best possible delegates of constituencies' majority will on every issue. Finally, measures of the quality of the ideological and issue representation that politicians provide actually correlate minimally, even though they are often treated as synonymous in research that seeks to identify which legislators represent their constituents better. In SI-2, we also show that the fact citizens have increased less in measured polarization than have politicians over the last several decades is also not sufficient to demonstrate that politicians represent citizens more poorly today than they did in the past.

These unexpected findings arise from the Delegate Paradox, by which a legislator who represents their constituents' issue views as well as possible may appear ideologically polarized even if their constituents do not. This is because, within a constituency, one ideological side often garners shifting majorities of citizens across issues even if few citizens consistently favor that side across them all. In a series of revealed preference experiments and an externally validated observational study, we showed that citizens do value whether politicians match their views on these individual issues-but that there is no evidence they value whether a politician's positions collectively suggest they are ideologically extreme.

Our findings have intriguing implications for American politics research more broadly. High levels of elite polarization are often interpreted as evidence that politicians ignore public opinion (e.g., Achen and Bartels 2016), but we have shown that polarization could result in part from politicians heeding public opinion-which there is plenty of evidence they do (Lax and Phillips 2009). In addition, the Delegate Paradox arises because the ostensibly monolithic moderate American public does not in fact share a consensus on most issues; this suggests any representative is guaranteed to disappoint many citizens with any given vote, a potential source of citizens' frustration with government future research could explore. Another possibility our findings raise is that measured polarization; little evidence supports this claim (e.g., McGhee et al. 2013). 
the Delegate Paradox could incentivize politicians to vote in a "polarized" manner, but that the aggregate consequences of these incentives make it more difficult to govern (Mann and Ornstein 2013).

Most importantly, our findings have implications for scholars who inform debates about the merits of changes to American political institutions. Scholars frequently judge these changes' success by whether they led politicians to be measured as more ideologically moderate, and thus less polarized (see Table SI-2). We believe these studies' conclusions should be considered more tentative. Currently, scholars run the risk of concluding any politician with a mix of liberal and conservative positions is a superior representative of most Americans' views—even Donald Trump.

We readily allow that the rudimentary conceptualization of issue representation we have offered here can be improved upon further, such as by incorporating which issues are most important to citizens or by estimating multiple underlying dimensions, such as separate dimensions by issue area. As future research incorporates these nuances, how scholars conceptualize representation should be informed not by what statistical assumptions are most convenient for scholars to make, but by citizens' judgments about who best represents them.

\section{References}

Achen, Christopher H. 1978. "Measuring Representation.” American Journal of Political Science 22:475-510.

Achen, Christopher H. and Larry M. Bartels. 2016. Democracy for realists: Why elections do not produce responsive government. Princeton University Press.

Ansolabehere, Stephen and Philip E. Jones. 2010. “Constituents' Responses to Congressional Roll-Call Voting." American Journal of Political Science 54(1):583-597.

Bafumi, Joseph and Michael C. Herron. 2010. "Leapfrog Representation and Extremism: A 
Study of American Voters and Their Members in Congress." American Political Science Review 104(3):519-542.

Baldassarri, Delia and Andrew Gelman. 2008. "Partisans without Constraint: Political Polarization and Trends in American Public Opinion.” American Journal of Sociology 114(2):408-446.

Bonica, Adam. 2014. "Mapping the Ideological Marketplace.” American Journal of Political Science 58(2):367-386.

Boudreau, Cheryl, Christopher S. Elmendorf and Scott A. MacKenzie. 2015. "Lost in Space? Information Shortcuts, Spatial Voting, and Local Government Representation.” Political Research Quarterly 68(4):843-855.

Broockman, David E. 2016. “Approaches to Studying Policy Representation.” Legislative Studies Quarterly 41(1):181-215.

Converse, Philip E. 1964. The Nature of Belief Systems in Mass Publics. In Ideology and Discontent, ed. David E. Apter. Ann Arbor: University of Michigan Press.

Erikson, Robert and Gerald Wright. 2012. Voters, Candidates, and Issues in Congressional Elections. In Congress Reconsidered, ed. Lawrence C. Dodd and Bruce I. Oppenheimer. 10 ed. Washington, DC: CQ Press pp. 91-116.

Fiorina, Morris P. and Samuel J. Abrams. 2009. Disconnect: The Breakdown of Representation in American Politics. University of Oklahoma Press.

Fowler, Anthony and Andrew B Hall. 2012. "Conservative Vote Probabilities: An Easier Method for the Analysis of Roll Call Data.".

Jessee, Stephen. 2016. “(How) Can We Estimate the Ideology of Citizens and Political Elites on the Same Scale?" American Journal of Political Science 60(4):1108-1124. 
Jessee, Stephen A. 2009. "Spatial Voting in the 2004 Presidential Election." American Political Science Review 103:59-81.

Kinder, Donald R. and David O. Sears. 1985. Public Opinion and Political Action. In The Handbook of Social Psychology, ed. G. Lindzey and E. Aronson. Vol. II Random House pp. 659-741.

Lax, Jeffrey R. and Justin H. Phillips. 2009. "Gay Rights in the States: Public Opinion and Policy Responsiveness.” American Political Science Review 103(3):367-85.

Lelkes, Yphtach. 2016. “Mass Polarization: Manifestations and Measurements.” Public Opinion Quarterly 80(S1):392-410.

Lenz, Gabriel S. 2012. Follow the Leader? How Voters Respond to Politicians' Performance and Policies. University of Chicago Press.

Mann, Thomas E. and Norman J. Ornstein. 2013. It's even worse than it looks: How the American constitutional system collided with the new politics of extremism. Basic Books.

Martin, Andrew D., Kevin M. Quinn and Jong Hee Park. 2011. "MCMCpack: Markov Chain Monte Carlo in R.” Journal of Statistical Software 42(9):22.

McGhee, Eric, Seth Masket, Boris Shor, Steven Rogers and Nolan McCarty. 2013. "A Primary Cause of Partisanship? Nomination Systems and Legislator Ideology." American Journal of Political Science 58(2):337-351.

Poole, Keith T. and Howard Rosenthal. 1997. Congress: A Political-Economic History of Roll Call Voting. Oxford University Press.

Tausanovitch, Chris and Christopher Warshaw. 2013. "Measuring Constituent Policy Preferences in Congress, State Legislatures and Cities.” Journal of Politics 75(2):330-342.

Willis, Derek. 2014. "Research Project Stirs Political Outrage in Montana.” New York Times. 